\title{
Changes in the polar vortex: Effects on Antarctic total ozone observations at various stations
}

\author{
B. Hassler, ${ }^{1,2}$ G. E. Bodeker, ${ }^{3}$ S. Solomon, ${ }^{2}$ and P. J. Young ${ }^{1,2}$ \\ Received 21 September 2010; revised 17 November 2010; accepted 30 November 2010; published 12 January 2011.
}

[1] October mean total column ozone data from four Antarctic stations form the basis for understanding the evolution of the ozone hole since 1960 . While these stations show similar emergence of the ozone hole from 1960 to 1980 , the records are divergent in the last two decades. The effects of long-term changes in vortex shape and location are considered by gridding the measurements by equivalent latitude. A clear eastward shift of the mean position of the vortex in October with time is revealed, which changes the fraction of ozone measurements taken inside/outside the vortex for stations in the vortex collar region. After including only those measurements made inside the vortex, ozone behavior in the last two decades at the four stations is very similar. This suggests that dynamical influence must be considered when interpreting and intercomparing ozone measurements from Antarctic stations for detecting ozone recovery and ozone-related changes in Antarctic climate. Citation: Hassler, B., G. E. Bodeker, S. Solomon, and P. J. Young (2011), Changes in the polar vortex: Effects on Antarctic total ozone observations at various stations, Geophys. Res. Lett., 38, L01805, doi:10.1029/ 2010GL045542.

\section{Introduction}

[2] The discovery of significant stratospheric ozone depletion in the mid-1980s [e.g., Farman et al., 1985], and the exposition of the chemistry responsible [e.g., Solomon et al., 1986; Molina and Molina, 1987], led to the enactment of the Montreal Protocol and its amendments and adjustments. Under the Protocol, emissions of ozone depleting substances (ODSs; compounds containing chlorine and bromine), were significantly reduced and global mean stratospheric ODS concentrations peaked in the late 1990s [Newman et al., 2007]. Since then questions about when the first signs of ozone recovery would be detectable, and when the ozone layer would be fully recovered, have attracted significant attention [Yang et al., 2005, 2008]. Addressing this issue is important not only for policymakers, but also because ozone recovery is expected to influence surface climate, particularly in Antarctica [Perlwitz et al., 2008] and over the Southern Hemisphere [Son et al., 2009].

\footnotetext{
${ }^{1}$ Cooperative Institute for Research in Environmental Sciences, University of Colorado at Boulder, Boulder, Colorado, USA

${ }^{2}$ Earth System Research Laboratory, NOAA, Boulder, Colorado, USA.

${ }^{3}$ Bodeker Scientific, Alexandra, New Zealand.
}

Copyright 2011 by the American Geophysical Union. 0094-8276/11/2010GL045542
[3] Yang et al. [2005, 2008] reported detection of the first stage of ozone recovery in Antarctic total column ozone, i.e. a statistically significant reduction in the rate of ozone decline due to changing halogen loading [World Meteorological Organization (WMO), 2007]. To evaluate whether the slowdown of the decline can be attributed to decreases in abundance of ODSs, Yang et al. [2008] adjusted the ozone data to account for changes in temperature (on the $440 \mathrm{~K}$ potential temperature surface) and ozone loss saturation. They also considered the coupling between ozone and temperature at $100 \mathrm{hPa}$ as an indicator for dynamical influences on the ozone variability, especially in the collar region of the polar vortex (a transition region between the vortex interior and mid-latitudes defined by significantly reduced meridional transport). Yang et al. [2005] noted that strong ozone-temperature coupling results from enhanced polar stratospheric cloud formation under colder conditions (and therefore more ozone destruction due to heterogeneous chemistry), as well as transport and mixing of mid-latitude air masses into the polar vortex. However, Yang et al. [2005, 2008] did not specify effects at particular locations, which is the focus of the present work.

[4] Several studies have highlighted recent changes in circulation and wave activity in the Southern Hemisphere stratosphere, which has the potential to affect circulation patterns and hence ozone distributions [Grytsai et al., 2007; Lin et al., 2009]. In this study, these lines of investigation are synthesized to evaluate how the evolution of October total column ozone at four Antarctic stations is influenced by systematic changes in Antarctic vortex dynamics. An elongated polar vortex, or one shifted away from the pole, induces a zonal asymmetry in the ozone field. Secular changes in those vortex attributes may then induce systematic changes in ozone at Antarctic stations. We explain why it is necessary to consider this influence when interpreting ozone changes at some stations, particularly those near the edge of the vortex. While satellite-based measurements have provided measurements of ozone over the sunlit portions of the Antarctic stratosphere since 1979, only these ground-based records extend back to 19581962. Understanding changes at these locations is key to revealing the full picture of the past evolution of the ozone hole and considering its future. The data used are described in Section 2. Section 3 characterizes the differences in October total column ozone changes at the four Antarctic stations, focusing on inter-station differences in ozone measurements in the last two decades. The equivalent latitude calculation used to classify the location of the measurements relative to the vortex edge is described in Section 4. In Section 5, the advantages and insights gained 

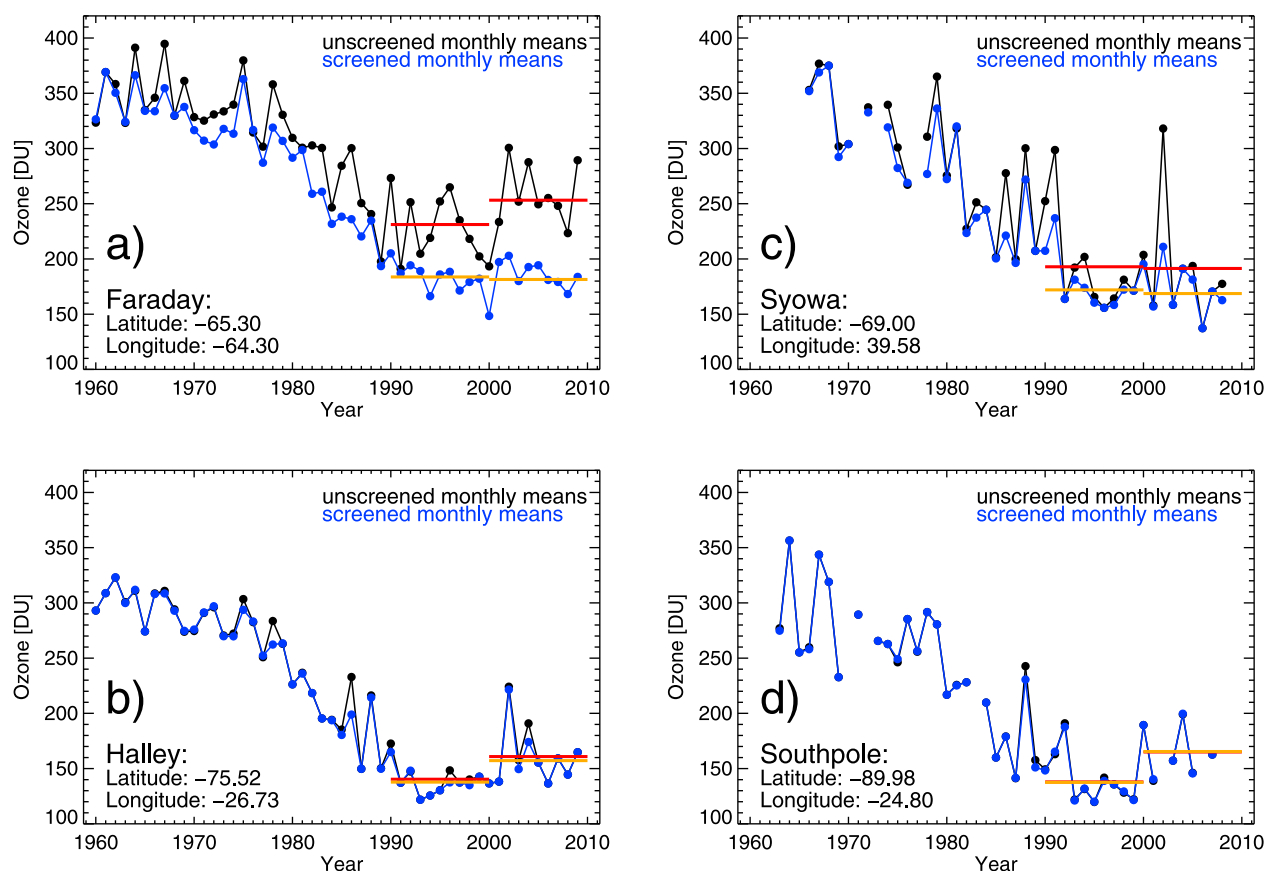

Figure 1. October mean total column ozone for four Antarctic stations: (a) Faraday/Vernadsky, (b) Halley, (c) Syowa and (d) South Pole. Black circles and lines represent means calculated from all available daily measurements. Blue circles and lines represent means calculated only from measurements taken from inside the polar vortex (screened). Red lines (orange lines) represent the October decadal means, 1990-1999 and 2000-2009, calculated from unscreened (screened) monthly means. Note that South Pole monthly means were calculated from measurements from the second half of October only.

following the equivalent latitude based sorting of the October ozone means are discussed.

\section{Data}

[5] Daily total column ozone measurements at South Pole, Syowa, Halley, and Faraday/Vernadsky were obtained from the World Ozone and Ultraviolet Radiation Data Center (WOUDC, http://www.woudc.org/index_e.html) and from the British Antarctic Survey (BAS, http://www.antarctica.ac. uk/met/jds/ozone/index.html\#data, stations Halley and Faraday/Vernadsky). October monthly means were calculated from the daily data from 1960 onwards, if at least 10 days of data were available in the month. At Faraday/Vernadsky and Halley only occasional daily measurements are missing in October between 1960 and 2009. At Syowa the measurement density for each October is not as high as for Halley and Faraday/Vernadsky, but is sufficient to calculate monthly means for most of the 1966-2008 period. However, the available daily measurements are generally well distributed throughout the month so that the October monthly means should not be biased to a particular part of the month. Exceptions to the minimum number of required daily data to calculate a valid October mean were made for South Pole since polar darkness precludes measurements in the first half of the month. At South Pole, valid monthly means required only seven daily values, such that most of the 1962-2008 period has valid October means.

[6] To calculate the location of the vortex edge, daily potential vorticity (PV) and wind fields on the $550 \mathrm{~K}$ potential temperature surface were extracted from NCEP/
NCAR reanalyses [Kalnay et al., 1996] and used as input to the algorithm described by Nash et al. [1996]. The choice of the $550 \mathrm{~K}$ surface as the basis for this analysis follows Bodeker et al. [2002].

[7] Stratospheric temperature measurements were taken from the Remote Systems Sensing retrieval (version 3.2) of the combined time series of channel 4 of the Microwave Sounding Unit (MSU) and channel 9 of the Advanced MSU (AMSU), known as MSU TLS [Mears and Wentz, 2009]. The MSU TLS weighting function peaks at approximately $80 \mathrm{hPa}(18 \mathrm{~km})$, with a half power range covering $150-50 \mathrm{hPa}(14-21 \mathrm{~km})$. In the polar regions this pressure range covers the entire lower stratosphere.

\section{Recent Total Column Ozone Measurements}

[8] Figure 1 shows the time series of October mean ozone at the four selected stations. As detailed above, October means are available at all of these stations almost continuously from 1960 to 2009. In addition to year-toyear variability, all of these stations show a distinct decline in ozone from the 1970s to the 1990s (black lines in Figure 1). The decline slows during the early 1990s. During the last two decades the ozone behavior at different stations can be quite different. The October mean ozone shows an apparent increase of approximately 20 DU from the 1990s to the 2000s at Faraday/Vernadsky, Halley and South Pole (Figure 1, black lines, unscreened data). In contrast, the October means for the 2000s at Syowa are on average $\sim 6$ DU lower than during the 1990s. This difference cannot be explained simply by high year-to-year 


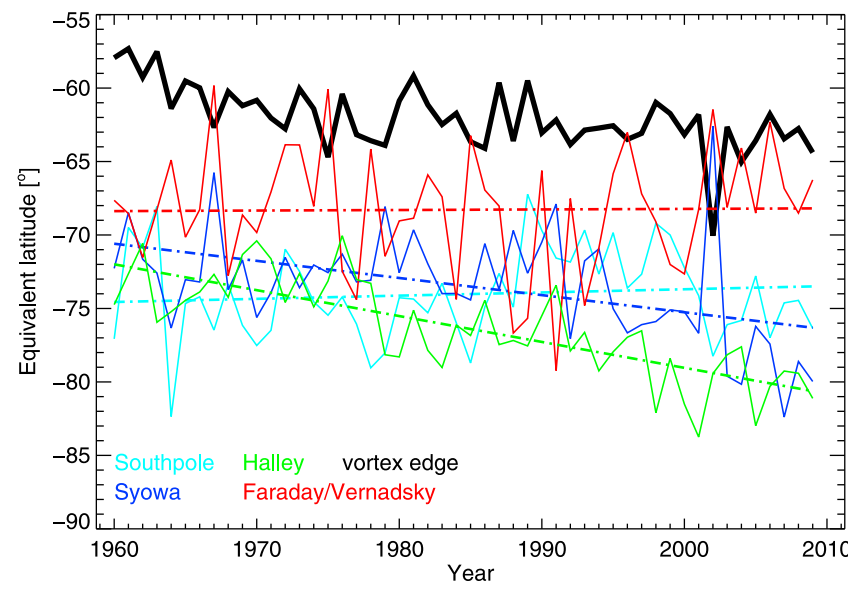

Figure 2. October mean equivalent latitude values for the Antarctic stations Faraday/Vernadsky (red solid line), Syowa (blue solid line), Halley (green solid line) and South Pole (cyan solid line) and the location of the vortex edge (black solid line). Dashed lines represent the linear fit to the respective October mean equivalent latitude values for each station.

variability caused by unusually variable dynamics in the Southern Hemisphere during the last decade [Langematz and Kunze, 2006; WMO, 2007], nor can it be attributed to differences in latitude since Syowa is located between Faraday/Vernadsky and Halley. The latter two stations both show an increase in decadal mean ozone, whereas Syowa's decadal mean ozone decreases. Reasons for this divergent behavior during recent decades will be discussed in the following sections.

\section{Vortex Dynamics and Equivalent Latitude Mapping}

[9] The chemical composition of air masses inside and outside the polar vortex is very different [e.g., Loewenstein et al., 1989]. To differentiate between measurements of the composition of such air masses, it is necessary to define the location of the vortex edge. In this study a PV isoline, with an associated equivalent latitude, demarcating the vortex edge was defined as in the work of Nash et al. [1996]. A PV value on the $550 \mathrm{~K}$ surface at the location of an ozone measurement can be used to define an equivalent latitude for the measurement, which can then be used to determine the location of the measurement relative to the vortex edge. Because of displacements of the vortex, the equivalent latitude at any station is not constant.

[10] This equivalent latitude remapping was applied to the daily data from all four stations so as to include only those measurements taken inside the vortex in the calculation of the October monthly means. Measurements were considered as representing air masses from inside the vortex if they were taken more than four degrees in equivalent latitude poleward of the vortex edge on the respective day. By screening the data with respect to their location relative to the vortex edge, ozone changes due to changes in vortex dynamics are significantly reduced so that any chemically driven ozone changes can be identified. Figure 1 shows both the October means calculated from all days in October (black lines), as well as the October means calculated using only those measurements made inside the vortex (blue lines). This screening only resulted in noticeable changes in the monthly means for Halley and South Pole (Figures $1 \mathrm{~b}$ and 1d, respectively) in some years, e.g. 2002, but affects the monthly means for Syowa and especially Faraday/ Vernadsky more dramatically. After screening, the longterm ozone behavior appears more consistent at the four stations. This suggests a dynamical rather than a chemical cause for the different behavior in ozone in recent decades. Therefore, if Faraday/Vernadsky data were to be used to diagnose ozone recovery in Antarctica the use of unscreened data would provide a misleading picture.

[11] One possible contribution to the inter-station differences seen in Figure 1 (black lines) is a change in the vortex size. However, as shown in Figure 2 (black line), we find that the October average vortex edge was close to $62^{\circ} \mathrm{S}$ (equivalent latitude) throughout the period from mid1960s to 2009 indicating little change in vortex area over this period. This equivalent latitude value for the vortex edge agrees well with the analyses of Bodeker et al. [2002] $\left(\sim 62^{\circ} \mathrm{S}\right)$ and Karpetchko et al. [2005] $\left(\sim 63^{\circ} \mathrm{S}\right)$.

[12] The October mean equivalent latitudes for each of the four Antarctic stations (Figure 2, colored lines) show decreases of $5-8^{\circ}$ in equivalent latitude at Syowa (dark blue line) and Halley (green line) suggesting that systematic shifts in the location of the vortex have resulted in these stations more frequently sampling air deeper within the vortex. In contrast, at South Pole (light blue line) and Faraday/Vernadsky (red line), changes in equivalent latitude are small. While there is no significant trend in equivalent latitude at Faraday/Vernadsky, the station is closer to the vortex edge after about 2000. As the size of the vortex did not change over the 40-year period, the differences in the mean equivalent latitude for the four stations are more likely caused by changes in vortex location with respect to the different stations.

[13] The fraction of all available daily measurements taken from inside or outside the vortex shows little change for South Pole (inside: $\sim 98 \%$, outside: $\sim 0.5 \%$, collar region: $\sim 1.5 \%$ ), while the fraction of measurements made inside the vortex increased for Syowa and Halley (from $\sim 88 \%$ to $\sim 96 \%$, and $\sim 92 \%$ to $\sim 98 \%$, respectively, excluding 2002 ). In contrast, the fraction of measurements taken inside the vortex at Faraday/Vernadsky decreased (from $\sim 68 \%$ to $\sim 58 \%$, excluding 2002), particularly during the last decade. These findings are consistent with a persistent eastward shift in the mean location of the vortex [Huth and Canziani, 2003; Malanca et al., 2005].

[14] The vortex shift can also be inferred from stratospheric temperature fields. Figure 3 a shows ten-year climatologies of the zonally asymmetric component of MSU TLS temperature ( $T$ minus zonal mean $T, T^{*}$ ) for October. During the three decades, the longitude of the $\mathrm{T}^{*}$ minimum moves eastward from about $44^{\circ} \mathrm{W}$ to $1^{\circ} \mathrm{E}$ (as indicated by the thick black lines in Figure $3 \mathrm{a}$ ), which corresponds to an eastward shift of about $21.5 \pm 11.6^{\circ} \mathrm{E}$ per decade (see Figure $3 b$ ). This shift is related to changes in the quasistationary wave number 1 [Grytsai et al., 2007; Lin et al., 2009]. Grytsai et al. [2007] showed that the longitude of the region of minimum temperatures in the vortex moved eastward at $16.4 \pm 5.2^{\circ} \mathrm{E}$ per decade at $65^{\circ} \mathrm{S}$, and at $21.2 \pm$ $7.3^{\circ} \mathrm{E}$ per decade at $75^{\circ} \mathrm{S}$. Although the time series of total column ozone analyzed by Grytsai et al. [2007] was shorter 
(a) $T^{*}$ climatologies for October

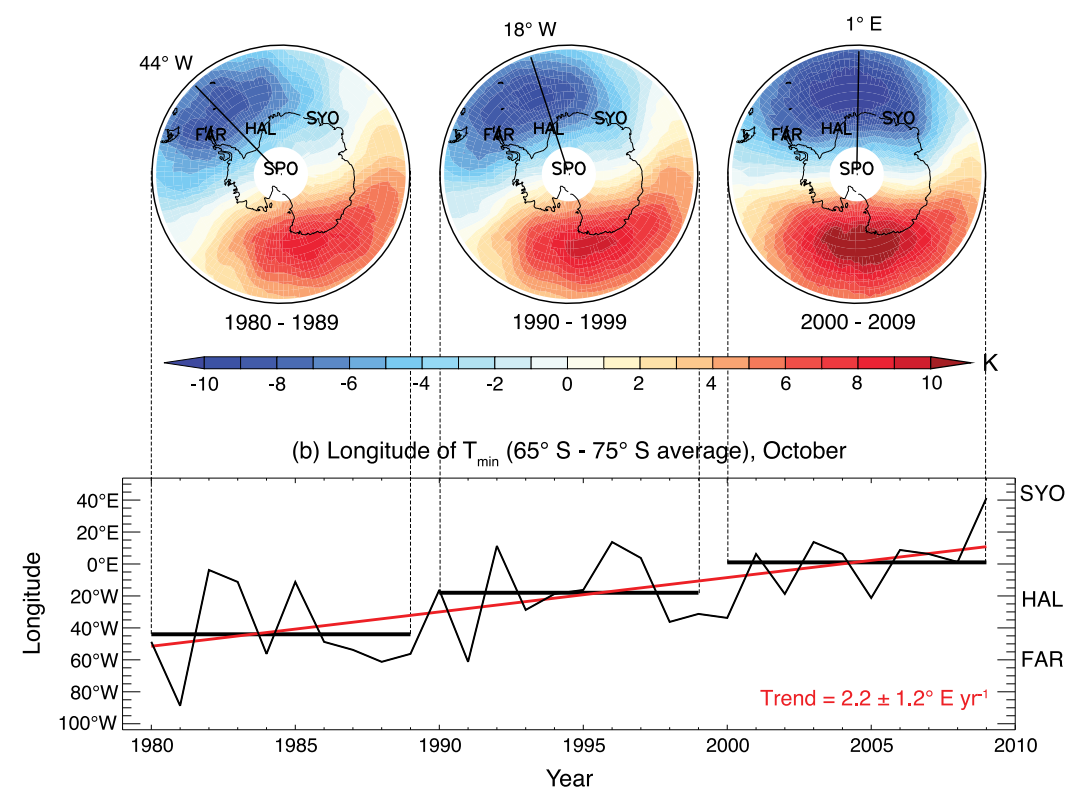

Figure 3. (a) Ten year climatologies of zonally asymmetric component of MSU TLS temperature (T*) for October. Plots also indicate the location of the measurements stations (FAR: Faraday/Vernadsky; HAL: Halley; SYO: Syowa: SPO: South Pole). (b) Time series and trend of the longitude at the minimum temperature $\left(\mathrm{T}_{\min }\right)$ for $65^{\circ} \mathrm{S}-70^{\circ} \mathrm{S}$ average for October. Ten-year averages of the $\mathrm{T}_{\text {min }}$ longitude are indicated by thick black lines (Figures $3 \mathrm{a}$ and $3 \mathrm{~b}$ ), corresponding to the $\mathrm{T}^{*}$ climatologies in Figure 3a. Longitudes of the stations (not SPO) are indicated on the right hand y-axis in Figure 3b; uncertainty for the trend (red line) corresponds to $\pm 2 \sigma$.

(1979-2005) than in this study, results from the zonally asymmetric temperature component in Figure 3 agree well with theirs.

\section{Discussion and Conclusion}

[15] The analysis presented above suggests systematic shifts in the position of the Antarctic vortex biases the sampling of air masses at stations close to the vortex edge. By screening total column ozone measurements according to their location with respect to the vortex edge the influence of the vortex shift on October means can be diagnosed (Figure 1, blue lines). For Halley and South Pole (Figures 1b and $1 \mathrm{~d}$, respectively) the screening has a noticeable effect only in some years (e.g. 2002), and the resultant change in decadal means is less than 5 DU. These stations are located at geographical latitudes of $75.52^{\circ} \mathrm{S}$ and $89.98^{\circ} \mathrm{S}$ respectively, and are far enough away from the vortex edge as to be unaffected by the shift in vortex location. In contrast, at Syowa the screening substantially reduces the higher monthly means, whereas the lower values remain almost unchanged (Figure 1c). This effect can be clearly seen in the decadal means over the last two decades (orange and red lines in Figure 1c). With a geographical latitude of $69^{\circ} \mathrm{S}$, Syowa is located close enough to the vortex edge such that small disturbances of the vortex have a noticeable effect on ozone measurements. However, Figure 3 shows that Syowa's location is to the east of the displaced vortex, in the direction of the vortex's movement. During recent years, Syowa has therefore been located closer to the center of the vortex, reducing the effects of vortex disturbances on ozone. This is mirrored in the closeness of the blue and the black line in Figure 1 during the 2000s (with the exception of 2002) compared to the earlier decades.

[16] The screening of the October ozone data shows the most pronounced effect at Faraday/Vernadsky. As for Syowa, Faraday/Vernadsky is located close enough to the vortex edge $\left(65.3^{\circ} \mathrm{S}\right)$ for small dynamical disturbances of the polar vortex to affect ozone measurements. While differences between screened and unscreened monthly means are apparent throughout the time series, the time series diverge during the last two decades. By screening for measurements made from inside the vortex, it becomes clear that the high October ozone measurements at Faraday/ Vernadsky are not caused by a reduced effect of chlorine on ozone (changes in polar chemistry) but instead linked to changes in the vortex location (changes in polar stratospheric dynamics). With the vortex shifting to the east, the edge of the vortex moves closer to Faraday/Vernadsky (see Figure 2) and a greater portion of the ozone measurements are in air from the collar region or outside the vortex where ozone values are higher.

[17] This analysis demonstrates how the interpretation of ozone station data is influenced by the observed shift in the Antarctic vortex. It shows the importance of accounting for dynamical influences in interpreting whether (and how) slowly decreasing concentrations of stratospheric chlorine and bromine may be affecting ozone. According to Newman et al. [2006], effects of the changes in equivalent effective stratospheric chlorine (EESC) concentrations should be moderate during the first years after reaching peak concentrations, so that those changes do not instantaneously have a direct effect on the amount of Antarctic ozone depletion. The decline in EESC concentrations is slowest at high latitudes [WMO, 2010], due to longer transport times of 
atmospheric chlorine there, which will delay the detection of a significant reduction of ozone loss compared to the midlatitudes. In accordance with the slow decline of ODSs in the polar stratosphere, results by Hofmann et al. [2009] show that ozonesonde observations at the South Pole during the last decade reveal that more than $90 \%$ of the ozone is still removed each year at around $70 \mathrm{hPa}$, similar to the ozone destruction in the mid 1990s. Dynamical changes (shifts in the vortex location) therefore provide a more plausible explanation for the divergent behavior of total column ozone data at the four Antarctic stations than changes in polar stratospheric chemistry.

[18] Just as the analysis in this study provides insights into ozone changes and the detection of recovery of the ozone hole, it also provides a set of Antarctic ozone measurements made exclusively inside the vortex suitable for looking for the onset of ozone decline within the vortex as the ozone hole began to form. For those stations with sufficient data, a $\mathrm{t}$-test diagnosis of 5 year populations of October monthly means shows that statistically significant divergence from the 1960-1964 climatology, at the $2 \sigma$ level, occurs in 19761980 for Halley and 1979-1983 for Faraday/Vernadsky. The same results are obtained by analyzing the unscreened data. This means that there is no indication of a statistically significant reduction in ozone at the $2 \sigma$ level at these Antarctic stations prior to 1980 , i.e., a change outside the bounds of natural variability cannot be detected.

[19] Acknowledgments. We would like to thank WOUDC and BAS for providing the total column ozone data and all people involved in obtaining the measurements and processing the data.

\section{References}

Bodeker, G. E., H. Struthers, and B. J. Connor (2002), Dynamical containment of Antarctic ozone depletion, Geophys. Res. Lett., 29(7), 1098, doi:10.1029/2001GL014206.

Farman, J. C., B. G. Gardiner, and J. D. Shanklin (1985), Large losses of total ozone in Antarctica reveal seasonal ClOx/NOx interaction, Nature, 315, 207-210, doi:10.1038/315207a0.

Grytsai, A. V., O. M. Evtushevsky, O. V. Agapitov, A. R. Klekociuk, and G. P. Milinevsky (2007), Structure and long-term change in the zonal asymmetry in Antarctic total ozone during spring, Ann. Geophys., 25, 361-374, doi:10.5194/angeo-25-361-2007.

Hofmann, D. J., B. J. Johnson, and S. Oltmans (2009), Twenty-two years of ozonesonde measurements at the South Pole, Int. J. Remote Sens., 30 (15), 3995-4008, doi:10.1080/01431160902821932.

Huth, R., and P. O. Canziani (2003), Classification of hemispheric monthly mean stratospheric potential vorticity fields, Ann. Geophys., 21, 805817, doi:10.5194/angeo-21-805-2003.

Kalnay, E., et al. (1996), The NCEP/NCAR 40-year reanalysis project, Bull. Am. Meteorol. Soc., 77(3), 437-471, doi:10.1175/1520-0477 (1996)077<0437:TNYRP>2.0.CO;2.

Karpetchko, A., E. Kyrö, and B. M. Knudsen (2005), Arctic and Antarctic polar vortices 1957-2002 as seen from the ERA-40 reanalyses, J. Geophys. Res., 110, D21109, doi:10.1029/2005JD006113.
Langematz, U., and M. Kunze (2006), An update on dynamical changes in the Arctic and Antarctic stratospheric polar vortices, Clim. Dyn., 27(6), 647-660, doi:10.1007/s00382-006-0156-2.

Lin, P., Q. Fu, S. Solomon, and J. M. Wallace (2009), Temperature trend patterns in Southern Hemisphere high latitudes: Novel indicators of stratospheric change, J. Clim., 22(23), 6325-6341, doi:10.1175/ 2009JCLI2971.1.

Loewenstein, M., J. R. Podolske, K. R. Chan, and S. E. Strahan (1989), Nitrous oxide as a dynamical tracer in the 1987 airborne Antarctic ozone experiment, J. Geophys. Res., 94(D9), 11,589-11,598, doi:10.1029/ JD094iD09p11589.

Malanca, F. E., P. O. Canziani, and G. A. Argüello (2005), Trends evolution of ozone between 1980 and 2000 at midlatitudes over the Southern Hemisphere: Decadal differences in trends, J. Geophys. Res., 110, D05102, doi:10.1029/2004JD004977.

Mears, C., and F. J. Wentz (2009), Construction of the Remote Sensing Systems v3.2 atmospheric temperature records from the MSU and AMSU microwave sounders, J. Atmos. Oceanic Technol., 26, 10401056, doi:10.1175/2008JTECHA1176.1.

Molina, L. T., and M. J. Molina (1987), Production of $\mathrm{Cl}_{2} \mathrm{O}_{2}$ from the selfreaction of the $\mathrm{ClO}$ radical, J. Phys. Chem., 91(2), 433-436, doi: $10.1021 / \mathrm{j} 100286 \mathrm{a} 035$.

Nash, E. R., P. A. Newman, J. E. Rosenfield, and M. R. Schoeberl (1996), An objective determination of the polar vortex using Ertel's potential vorticity, J. Geophys. Res., 101(D5), 9471-9478, doi:10.1029/ 96JD00066.

Newman, P. A., E. R. Nash, S. R. Kawa, S. A. Montzka, and S. M. Schauffler (2006), When will the Antarctic ozone hole recover?, Geophys. Res. Lett., 33, L12814, doi:10.1029/2005GL025232.

Newman, P., J. S. Daniel, D. Waugh, and E. R. Nash (2007), A new formulation of equivalent effective stratospheric chlorine (EESC), Atmos. Chem. Phys., 7, 4537-4552, doi:10.5194/acp-7-4537-2007.

Perlwitz, J., S. Pawson, R. L. Fogt, J. Nielsen, and W. D. Neff (2008), Impact of stratospheric ozone hole recovery on Antarctic climate, Geophys. Res. Lett., 35, L08714, doi:10.1029/2008GL033317.

Solomon, S., R. R. Garcia, F. S. Rowland, and D. J. Wuebbles (1986), On the depletion of Antarctic ozone, Nature, 321, 755-758, doi:10.1038/ $321755 \mathrm{a} 0$.

Son, S.-W., N. F. Tandon, L. M. Polvani, and D. W. Waugh (2009), Ozone hole and Southern Hemisphere climate change, Geophys. Res. Lett., 36, L15705, doi:10.1029/2009GL038671.

World Meteorological Organization (WMO) (2007), Scientific Assessment of Ozone Depletion: 2006, Global Ozone Research and Monitoring Project, Rep. 50, Geneva, Switzerland.

World Meteorological Organization (WMO) (2010), Executive Summary: "Scientific Assessment of Ozone Depletion: 2010," Geneva, Switzerland.

Yang, E. S., D. M. Cunnold, M. J. Newchurch, and R. J. Salawitch (2005), Change in ozone trends at southern high latitudes, Geophys. Res. Lett., 32, L12812, doi:10.1029/2004GL022296.

Yang, E. S., D. M. Cunnold, M. J. Newchurch, R. J. Salawitch, M. P. McCormick, J. M. Russell III, J. M. Zawodny, and S. J. Oltmans (2008), First stage of Antarctic ozone recovery, J. Geophys. Res., 113, D20308, doi:10.1029/2007JD009675.

G. E. Bodeker, Bodeker Scientific, 42 Young Lane RD1, Alexandra, Central Otago 9391, New Zealand.

B. Hassler and P. J. Young, Cooperative Institute for Research in Environmental Sciences, University of Colorado at Boulder, Boulder, CO 80309, USA.

S. Solomon, Earth System Research Laboratory, NOAA, 325 Broadway, Boulder, CO 80305, USA. 